\title{
26 Research Square \\ Hereditary Spherocytosis With Liver Transplantation After Cirrhosis: a Case Report
}

\section{Xueliang Yang}

The First Affiliated Hospital of Xi'an Jiaotong University

\section{Wen Wang}

The First Affiliated Hospital of Xi'an Jiaotong University

\section{Wanhu Fan}

The First Affiliated Hospital of Xi'an Jiaotong University

\section{Lin Cai}

Shaanxi Provincial Cancer Hospital

\section{Feng Ye}

The First Affiliated Hospital of Xi'an Jiaotong University

\section{Shumei Lin}

The First Affiliated Hospital of Xi'an Jiaotong University

\section{Xiaojing Liu ( $\nabla$ xiaojing406@163.com )}

The First Affiliated Hospital of Xi'an Jiaotong University

\section{Case report}

Keywords: Hereditary spherocytosis, SPTB, Next-Generation Sequencing, cirrhosis

Posted Date: May 5th, 2021

DOI: https://doi.org/10.21203/rs.3.rs-466582/v1

License: (c) (1) This work is licensed under a Creative Commons Attribution 4.0 International License. Read Full License

Version of Record: A version of this preprint was published at Frontiers in Medicine on February 11th, 2022. See the published version at https://doi.org/10.3389/fmed.2022.823724. 


\section{Abstract}

Background: The clinical manifestations of hereditary spherocytosis are similar to those of various hemolytic anemias, which causes hereditary spherocytosis to be difficult to diagnose clinically.

Case presentation: In this case, we obtained the peripheral blood of a patient and family members, and through a whole exome test of the 6297 genetic phenotypes confirmed by OMIM, we found a heterozygous nonsense mutation (c.4117C>T, P.Q1373X) in the SPTB gene. Combined with the patient's clinical data, the diagnosis was hereditary spherocytosis. Compared with the public population sequence database, the mutation was found to be unique. Through protein structure prediction analysis and literature studies, we found that the mutation caused SPTB mRNA instability, resulting in insufficient spectral protein synthesis and affecting the integrity and flexibility of the red blood cell membrane skeleton. This case report found that SPTB gene mutations may cause liver dysfunction and cirrhosis in addition to hereditary spherocytosis, and this finding expands the phenotypic spectrum of SPTB. This study confirmed that NGS can be used to diagnose hereditary spherocytosis.

Conclusions: Identifying mutated genes can not only accurately treat diseases, but also avoid potential genetic risks and improve prenatal and postnatal care.

\section{Background}

Hereditary spherocytosis (HS) is a hereditary non-immune hemolytic disease that is characterized by the presence of spherical erythrocytes in peripheral blood smears (1). The prevalence of neonatal HS in northern European and North American countries is approximately $1 / 5000$ and $1 / 2000$, respectively, and the prevalence of neonatal HS in China is approximately $0.18 / 1$ million (2). The clinical presentation of HS varies widely from asymptomatic patients to severe anemia, jaundice, and hepatosplenomegaly. The diagnosis of HS is based primarily on clinical manifestations such as jaundice, splenomegaly, and gallstones, with laboratory examination confirming the presence of extravascular hemolysis (3). The above presentation is also common in thalassemia, thus, the two diseases can be easily confused.

HS is most commonly associated with autosomal dominant inheritance, and about $75 \%$ of HS cases are autosomal dominant. However, about $25 \%$ of patients have no family history, which may reflect autosomal recessive inheritance or newly emerged mutations (4). Patients with recessive inheritance usually have severe symptoms, such as severe life-threatening hemolysis $(5,6)$. The molecular pathogenesis of HS is due to gene mutations that cause defects in the anchor protein, spectrum protein, band 3 , or protein 4.2 , which constitute the erythrocyte membrane and lead to reduced denaturation of red blood cells and extrascular-hemolysis (7-9). Mutations in the ANK1 (Anchor 1), SPTB (Spectrin, Beta, erythrocytic), SPTA1 (Spectrin, alpha, erythrocytic 1), SLC4A1 (Solutic-carrier family 4, Member 1), and EPB42 (erythrocyte membrane protein band 4.2) genes have been found to cause HS (10-13). HS is mainly due to mutations in $A N K 1$ and SPTB genes in Chinese individuals (14). 
Next-generation sequencing (NGS) is a high-throughput and cost-effective sequencing technology that is capable of performing whole-exome sequencing. NGS mainly focused on the clinical diagnosis of genetically related diseases and facilities the discovery of potential pathogenic or mutant genes (15). This study reports a case of HS with liver transplantation after cirrhosis, summarizes its clinical manifestations, laboratory test results, and gene sequencing data, and conducts a bioinformatics analysis to improve our understanding and diagnoses of HS and our knowledge of the clinical outcomes of SPTB gene mutations.

\section{Case Presentation}

A 24-year-old woman presented at the First Affiliated Hospital of Xi'an Jiaotong University in September with jaundice for 24 years and liver cirrhosis for one year. She had been diagnosed with non-autoimmune hemolytic anemia 24 years ago, based on a medical history of persistent anemia and hyperbilirubinemia. Eight years later, she underwent splenectomy due to refractory anemia, severe jaundice, and splenomegaly. At 22 years of age, the jaundice reappeared with abdominal distension, liver discomfort, fatigue, anorexia, and fever. Laboratory tests showed a hemoglobin level of $110 \mathrm{~g} / \mathrm{L}$, platelet count of $198 \times 10^{9} / \mathrm{L}$, reticulocyte ratio of $15 \%$, aspartic transaminase level of $87.8 \mathrm{U} / \mathrm{L}$, glutamic transaminase level of $71 \mathrm{U} / \mathrm{L}$, total bilirubin level of $127 \mu \mathrm{mol} / \mathrm{L}$, and albumin level of $29.6 \mathrm{~g} / \mathrm{L}$. Peripheral blood smear tests showed visible round and densely colored spherical red blood cells, which lacked pale white centers and presented smaller diameters than normal red blood cells. A hemoglobin peptide chain analysis revealed no abnormalities. Hemolysis reaction, red blood cell osmotic fragility test, and G6PD activity were normal. Both the father and younger brother suffered from hemolytic anemia, and 16 years ago, her younger brother underwent splenectomy due to hemolytic anemia (Fig. 1).

To identify genetic factors of the disease, the peripheral blood of the proband, the proband's parents, and the proband's younger brother were obtained. The 6297 genetic phenotypes currently confirmed by OMIM were tested through a whole exome NGS analysis that focused on a total of 412 genes related to the subject's clinical phenotype. As a result, one heterozygous nonsense mutation, c.4117C > T,p.Q1373X (reference sequence: NM_001355436), was identified in exon 20 of the proband's SPTB gene, the proband's parents, and the proband's younger brother (Fig. 2).

SPTB gene abnormalities lead to hereditary spherocytosis type 2 with autosomal dominant inheritance (OMIM\#616649). In this test, we detected a nonsense variant in the SPTB gene of the proband that was inherited from her father, and the father and younger brother of the proband carried the same heterozygous variant. In autosomal dominant diseases, a single pathogenic variant can cause disease. The mutation was not found in public population sequence databases, including HGMD, 1000 Genomes Project Database, ESP6500, ExAC, and dbSNP. The mutation sequence was predicted in SWISS-MODEL, and it was found that the mutation of the $\beta$-spectrum protein p.Q1373X caused the early termination of the protein and subsequently triggered the loss of a-helix (Fig. 3). Based on clinical symptoms, laboratory tests, and NGS sequencing, the proband was diagnosed with HS. 
The hepatitis virus antibody, autoantibody, and autoimmune liver disease antibody screening were all negative. Furthermore, Epstein-Barr virus DNA and cytomegalovirus DNA were both negative. Screening for metabolic disorders such as hemochromatosis and hepatolenticular degeneration were normal, and no long-term heavy drinking, nutritional disorders, or exposure to industrial poisons or drugs were noted. With regards to 16,569 sites in the patient's mitochondrial gene, no abnormalities were found in 66 mutations that have been reported to cause disease. Re-analysis of the data of all exons did not reveal a second single-gene disease.

Later, she experienced severe upper gastrointestinal bleeding accompanied by hepatic encephalopathy and massive ascites, and her hemoglobin level was at least $50 \mathrm{~g} / \mathrm{L}$. Laboratory tests showed an aspartic transaminase level of $65 \mathrm{U} / \mathrm{L}$, glutamic transaminase level of $44 \mathrm{U} / \mathrm{L}$, total bilirubin level of $213.3 \mu \mathrm{mol} / \mathrm{L}$, albumin level of $33 \mathrm{~g} / \mathrm{L}$, plasma ammonia level of $97 \mu \mathrm{mol} / \mathrm{L}$, creatinine level of $64 \mu \mathrm{mol} / \mathrm{L}$, INR of 1.67 , and So MELD score of 22. Gastroscopy showed esophageal varices (Lemi D 2 Rf1), and computed tomography of the abdomen revealed liver cirrhosis, portal hypertension, massive abdominal and pelvic effusion, thickening of the gallbladder wall, and bilateral pleural effusion. Liver computed tomography angiography images showed a thin hepatic artery, portal hypertension, opening of the left gastric vein, and varicose veins in the lower part of the esophagus and stomach, which presented multiple nodules in the liver, with low-density shadows in the right leaf of the liver. Liver magnetic resonance imaging showed multiple patchy abnormal enhancements in the liver during the dynamic phase, and some of the cirrhotic nodules could be malignant. A liver biopsy was not performed because of coagulopathy.

The patient underwent classic orthotopic liver transplantation and portal vein thrombectomy in October 2019. Histopathological examination of the resected specimens revealed nodular liver cirrhosis and chronic cholecystitis. The portal vein thrombosis pathology showed thrombosis with organization (Fig. 4). At the follow-up more than one year after liver transplantation, the patient showed good signs of recovery.

\section{Discussion And Conclusions}

HS is a genetic disease caused by congenital abnormalities in the red blood cell membrane structure. The diagnosis of HS is usually based on a positive family history, spherocytosis, jaundice, hepatosplenomegaly, and anemia. The clinical manifestations of HS are similar to those of glucose-6phosphate dehydrogenase (G6PD) and Gilbert syndrome and are prone to misdiagnosis (5). The application of NGS is of great significance in the diagnosis of genetic diseases. It is not only beneficial for clinical diagnosis and treatment, but also important for genetic counseling. In this case, the proband, the proband's father, and the proband's younger brother presented an increase in red blood cell fragility due to unintentional mutations in the SPTB gene that caused anemia and jaundice. Our findings further confirm that heterozygous mutations in the SPTB gene cause HS.

The SPTB gene was first identified in red blood cells and is the main component of the membrane cytoskeleton. SPTB and red blood cell a-spectrum protein, through a2 $\beta 2$ allo-tetramerization, forms a 
dense red blood cell membrane skeleton network. This skeletal network is connected to the lipid bilayer to maintain the shape of the red blood cells $(1,16)$. SPTB gene mutations are inherited in an autosomal dominant manner. Among patients with HS in Northern Europe, SPTB mutations account for approximately $15-30 \%$ of cases. Furthermore, monoallelic SPTB mutations are among the most common causes of typical HS (1). Common types of SPTB mutations include splice sites, frameshifts, and nonsense mutations, which usually result in defects in mRNA processing and $\beta$-spectrum truncation (17). In this case, the SPTB gene heterozygous mutation (c.4117C $>T$ ) was unintentional, and resulted in a frameshift and a premature stop codon downstream of the C-terminal coding region of the dimer, which caused instability of the mutated mRNA and insufficient spectral protein synthesis and affected the integrity and flexibility of the erythrocyte membrane skeleton. The main clinical manifestation of this mutation is moderate or severe HS.

In addition to red blood cells, SPTB is mainly found in the bone marrow, heart, brain, placenta, and prostate tissue and is relatively low in the liver tissue. Recent research has found that SPTB also plays an important role in liver cell regeneration and repair. The $\beta /$ spectrum protein encoded by SPTB is reduced in hepatocellular carcinoma and cholangiocarcinoma cases, while it is expressed in normal hepatocytes and all focal nodular hyperplasia and liver adenoma (18). Homozygous SPTB gene mutations in newborns can cause severe transfusion-dependent hemolytic anemia, combined hyperbilirubinemia, coagulopathy, portal hypertension, massive ascites, and progressive liver failure (19). In this case, complete mitochondrial gene sequencing of the proband showed no abnormalities. Additionally, reanalysis of the data of all exons did not reveal a second single-gene disease to explain liver disease. We speculate that SPTB mutations may cause liver dysfunction and cirrhosis in addition to HS, and our findings expand the phenotypic spectrum of SPTB.

\section{List Of Abbreviations}

HS, Hereditary spherocytosis; ANK1,Anchor 1; SPTB, Spectrin, Beta, erythrocytic; SPTA1, Spectrin, alpha, erythrocytic 1; SLC4A1,Solutic-carrier family 4, Member 1; EPB42, erythrocyte membrane protein band 4.2; NGS, Next-generation sequencing; G6PD, glucose-6-phosphate dehydrogenase.

\section{Declarations}

\section{Acknowledgements}

This study was supported by institutional foundation of the first affiliated hospital of Xi'an jiaotong University.

\section{Authors' contributions}

All authors contributed to the study conception and design. Patient management, data collection, and analysis were performed by all authors listed as physicians. Further data analysis was performed by Xueliang Yang and Xiaojing Liu. Histopathological examination was Lin Cai. Materials were provided by 
Wen Wang. The first draft of the manuscript was written by Xueliang Yang, and all authors commented on previous versions of the manuscript. All authors read and approved the fnal manuscript.

\section{Funding}

This study was supported by institutional foundation of the first affiliated hospital of Xi'an jiaotong University 2018QN-13, Natural Science Foundation of Shaanxi Province 2017JM8083.

\section{Availability of data and materials}

All data generated or analyzed during this study are included in this published article.

\section{Ethics approval and consent to participate}

Approval was obtained from the Committee for the Protection of Human Subjects at the First Affiliated Hospital of Xi'an Jiaotong University. The procedures used in this study adhere to the tenets of the Declaration of Helsinki. Written informed consent was obtained from the patients.

\section{Consent for publication}

Informed consent was obtained from the the patients and her family.

\section{References}

1. Perrotta S, Gallagher PG, Mohandas N. Hereditary spherocytosis. Lancet (London, England). 2008;372(9647):1411-26.

2. Liu Y, Zheng J, Song L, Fang Y, Sun C, Li N, et al. A novel SPTB gene mutation in neonatal hereditary spherocytosis: A case report. Exp Ther Med. 2020;20(4):3253-9.

3. Farias MG. Advances in laboratory diagnosis of hereditary spherocytosis. Clinical chemistry and laboratory medicine. 2017;55(7):944-8.

4. Wang X, Zhang A, Huang M, Chen L, Hu Q, Lu Y, et al. Genetic and Clinical Characteristics of Patients With Hereditary Spherocytosis in Hubei Province of China. Front Genet. 2020;11:953.

5. He BJ, Liao L, Deng ZF, Tao YF, Xu YC, Lin FQ. Molecular Genetic Mechanisms of Hereditary Spherocytosis: Current Perspectives. Acta Haematol. 2018;139(1):60-6.

6. Bolton-Maggs PH, Langer JC, lolascon A, Tittensor P, King MJ, General Haematology Task Force of the British Committee for Standards in $\mathrm{H}$. Guidelines for the diagnosis and management of hereditary spherocytosis--2011 update. Br J Haematol. 2012;156(1):37-49.

7. Delaunay J. The molecular basis of hereditary red cell membrane disorders. Blood reviews. 2007;21(1):1-20.

8. Agre P, Orringer EP, Bennett V. Deficient red-cell spectrin in severe, recessively inherited spherocytosis. N Engl J Med. 1982;306(19):1155-61. 
9. Gallagher PG, Forget BG. Hematologically important mutations: spectrin and ankyrin variants in hereditary spherocytosis. Blood cells, molecules \& diseases. 1998;24(4):539-43.

10. Park J, Jeong DC, Yoo J, Jang W, Chae H, Kim J, et al. Mutational characteristics of ANK1 and SPTB genes in hereditary spherocytosis. Clin Genet. 2016;90(1):69-78.

11. Chonat S, Risinger M, Sakthivel H, Niss O, Rothman JA, Hsieh L, et al. The Spectrum of SPTA1Associated Hereditary Spherocytosis. Frontiers in physiology. 2019;10:815.

12. Tang X, Guo X, Gao J. A Novel Compound Heterozygous Mutation in SLC4A1 Gene Causing Severe Hereditary Spherocytosis and Distal Renal Tubular Acidosis. Indian journal of pediatrics. 2020;87(3):233-4.

13. Bruce LJ, Ghosh S, King MJ, Layton DM, Mawby WJ, Stewart GW, et al. Absence of CD47 in protein 4.2-deficient hereditary spherocytosis in man: an interaction between the Rh complex and the band 3 complex. Blood. 2002;100(5):1878-85.

14. Wang R, Yang S, Xu M, Huang J, Liu H, Gu W, et al. Exome sequencing confirms molecular diagnoses in 38 Chinese families with hereditary spherocytosis. Sci China Life Sci. 2018;61(8):947-53.

15. Qin L, Nie Y, Zhang H, Chen L, Zhang D, Lin Y, et al. Identification of new mutations in patients with hereditary spherocytosis by next-generation sequencing. Journal of human genetics. 2020;65(4):42734.

16. Van Dort HM, Knowles DW, Chasis JA, Lee G, Mohandas N, Low PS. Analysis of integral membrane protein contributions to the deformability and stability of the human erythrocyte membrane. The Journal of biological chemistry. 2001;276(50):46968-74.

17. Maciag M, Plochocka D, Adamowicz-Salach A, Burzynska B. Novel beta-spectrin mutations in hereditary spherocytosis associated with decreased levels of mRNA. $\mathrm{Br} \mathrm{J}$ Haematol. 2009;146(3):326-32.

18. Hu S, Jue D, Albanese J, Wang Y, Liu Q. Utilization of spectrins betal and betall in diagnosis of hepatocellular carcinoma. Ann Diagn Pathol. 2019;39:86-91.

19. Richmond CM, Campbell S, Foo HW, Lunke S, Stark Z, Moody A, et al. Rapid Identification of Biallelic SPTB Mutation in a Neonate with Severe Congenital Hemolytic Anemia and Liver Failure. Mol Syndromol. 2020;11(1):50-5.

\section{Figures}




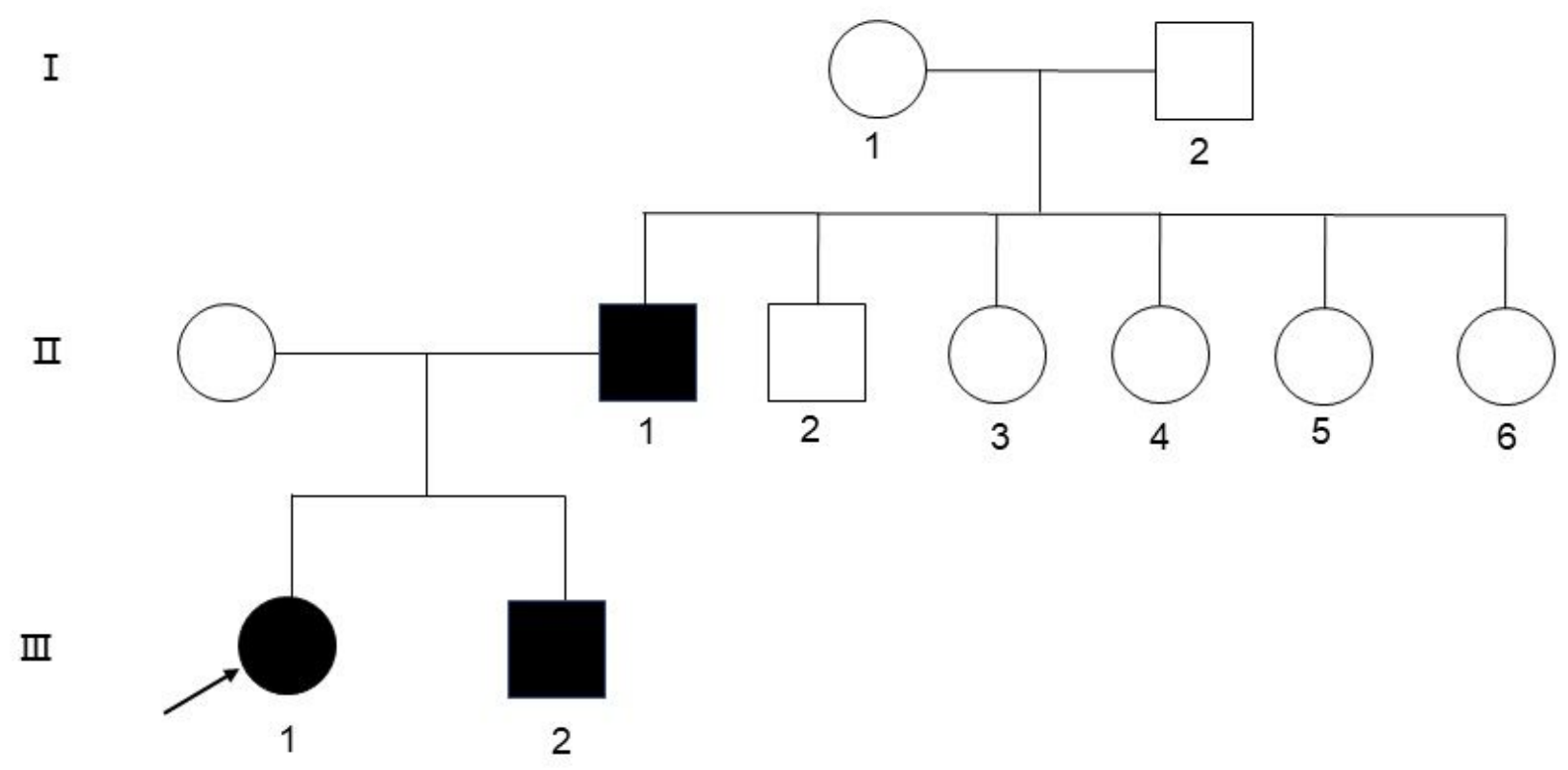

Figure 1

Family diagram of three patients $(\mathbb{1} 1, \otimes 1, \varangle 2$; the arrow shows the proband) 
A

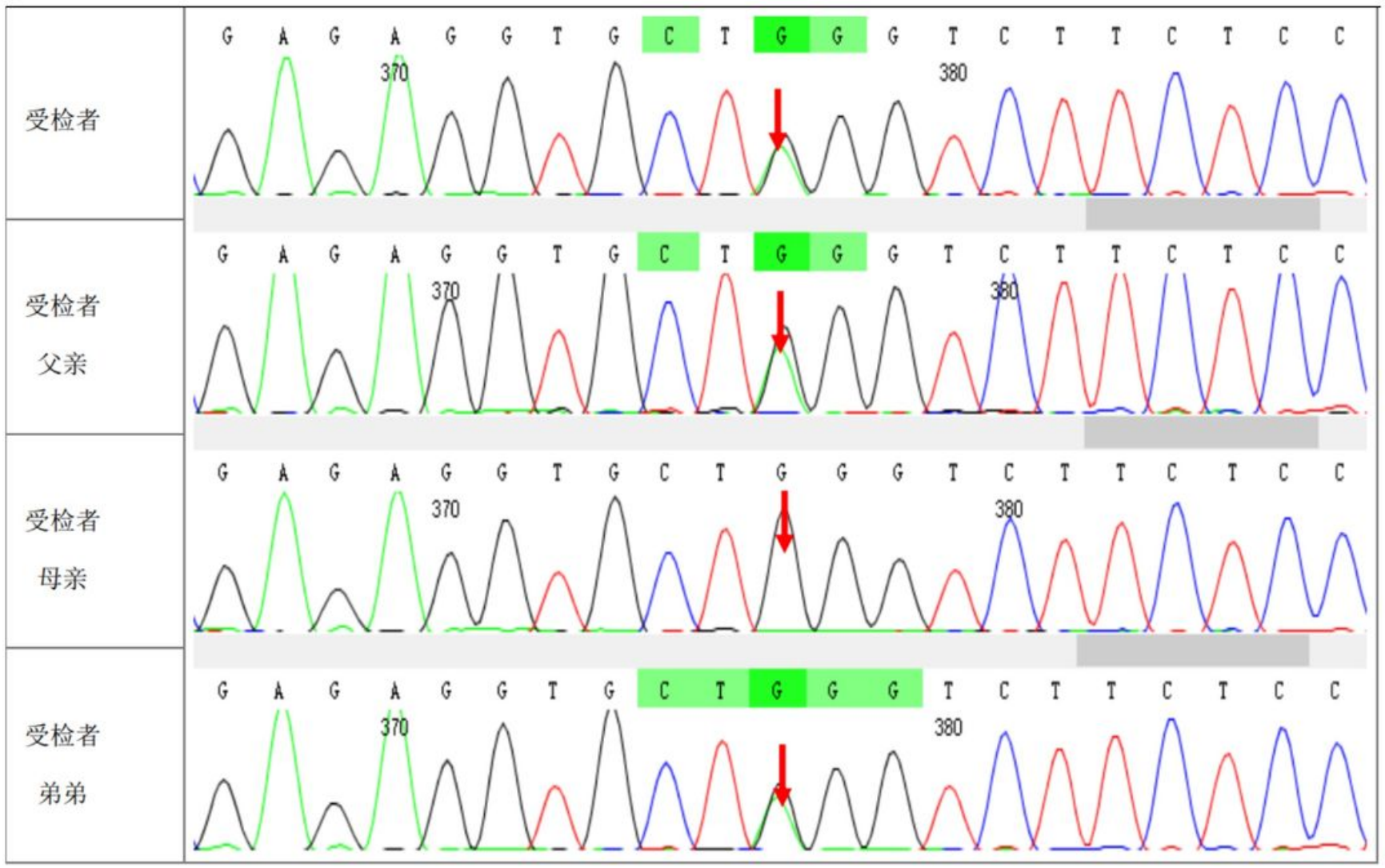

B
Wildtype
P.1361 -W--D--E--L--Q--A--T-- T-- K-- E-- K-- T--Q--H--L- 1375
C.4249 TGG GAC GAG CTG CAG GCC ACC ACA AAG GAG AAG ACC CAG CAC CTC
Mutant
P.1361 -W--D--E--L--Q--A--T-- T-- K-- E-- K--T--X
C.4249 TGG GAC GAG CTG CAG GCCACC ACA AAG GAG AAG ACC TAG

Figure 2

Mutation testing analysis of the SPTB amino acid sequence. A. NGS correlation peak map; B. wildtype and mutant SPTB sequences 
A

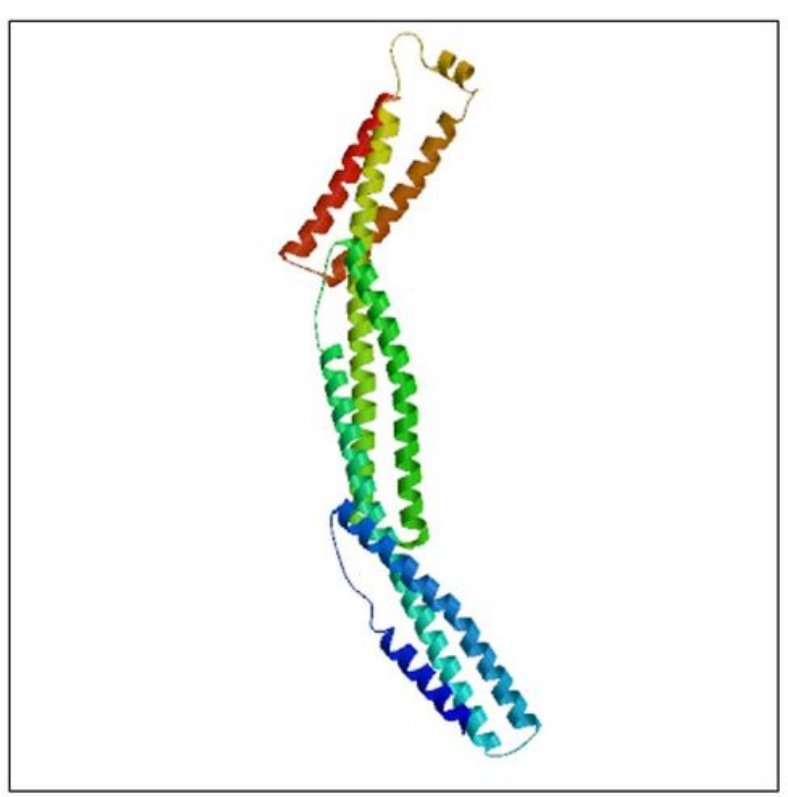

B

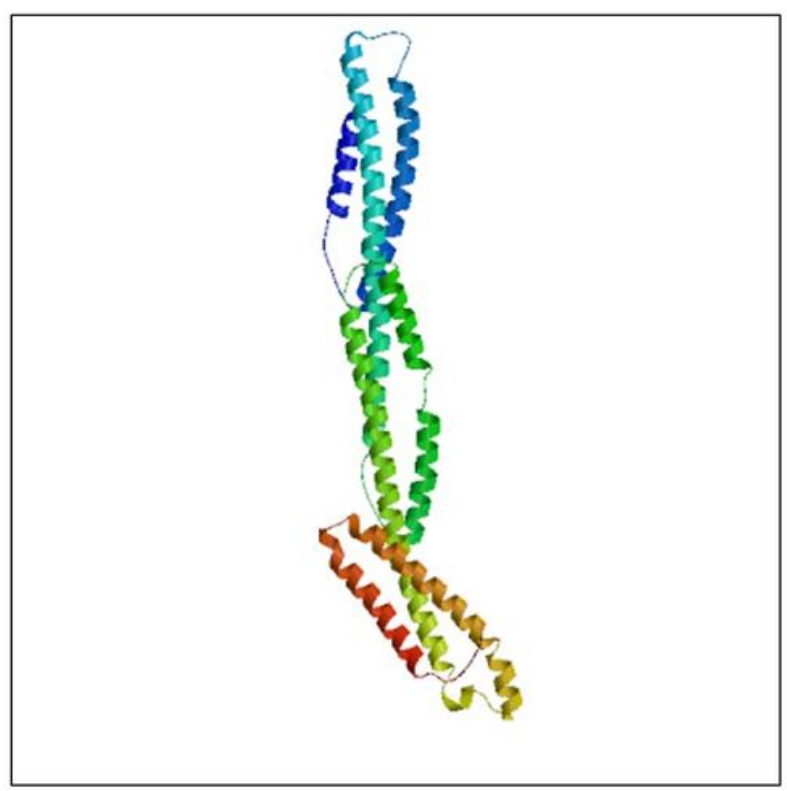

\section{Figure 3}

Prediction of SPTB protein structure by Swiss-model. A. wild type SPTB, B. mutant SPTB

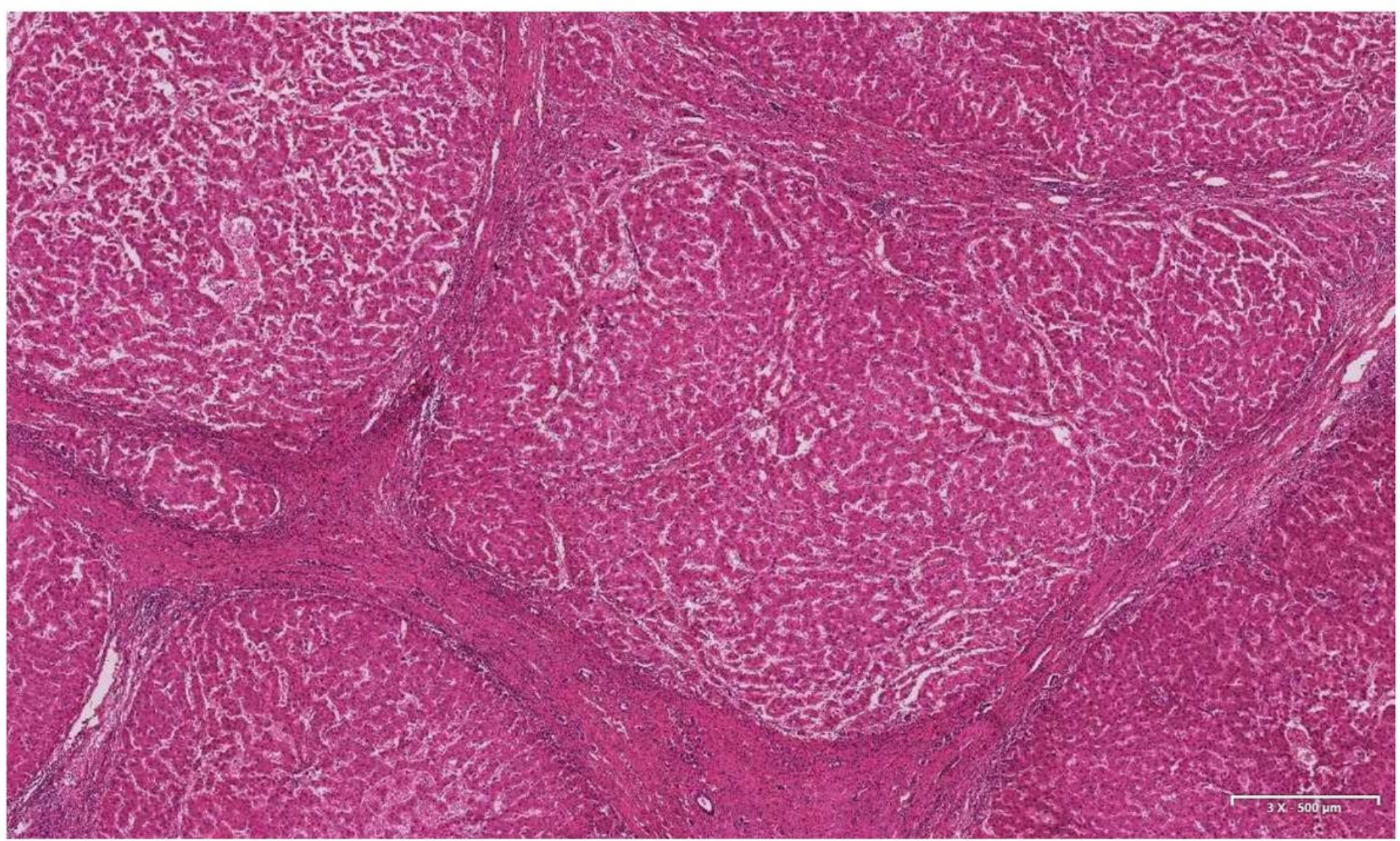

Figure 4 
Hepatectomy specimen pathology

Page $11 / 11$ 